\title{
Percepción docente sobre la Realidad Aumentada en la Enseñanza de Ciencias en Primaria. Análisis DAFO
}

\author{
Lourdes Villalustre Martínez \\ Departamento de CC de la Educación, Universidad de Oviedo. Oviedo.España.villalustrelourdes@uniovi.es \\ ORCID: http:// orcid.org/0000-0002-5427-5355
}

M. Esther del Moral Pérez

Departamento de CC de la Educación, Universidad de Oviedo. Oviedo. España. emoral@uniovi.es

ORCID: http:/ / orcid.org/0000-0002-9143-5960

María del Rosario Neira-Piñeiro

Departamento de CC de la Educación, Universidad de Oviedo. Oviedo.España.neiramaria@uniovi.es ORCID: http:/ / orcid.org/0000-0003-2355-4682

[Recibido: 4 Julio 2018. Revisado: 19 Noviembre 2018. Aceptado: 30 Abril 2019.]

\begin{abstract}
Resumen: Esta investigación pretende: a) identificar las posibilidades didácticas de la Realidad Aumentada (RA) para el aprendizaje científico en primaria percibidas por los docentes y b) efectuar un análisis DAFO relativo a su implementación en la enseñanza de ciencias. Para ello, se analizan - mediante un cuestionario- las percepciones de una muestra de docentes $(\mathrm{N}=41)$ participantes en el proyecto Experiment with Augmented Reality, impulsado por la Consejería de Educación asturiana (2017-18), donde participaron 542 alumnos; y posteriormente, al término de dicho proyecto, se llevó a cabo un análisis DAFO. Entre los resultados se destaca que el profesorado considera que la RA incrementa las competencias científicas del alumnado y su motivación hacia la ciencia, fomenta la colaboración y genera un clima de aula propicio para la indagación y el trabajo por proyectos. Sin embargo, se detectan dificultades como la escasa formación docente y la precariedad de los recursos tecnológicos de las escuelas.
\end{abstract}

Palabras clave: realidad aumentada, contenidos científicos, competencia científica, educación primaria.

Teachers'perception about augmented reality for teaching science in primary education. SWOT Analysis.

Abstract: The aims of this research are: a) to identify the educational possibilities of Augmented Reality (AR) for Science learning in primary education, according to the teachers' perception, and b) to do a SWOT analysis related to AR implementation in Science teaching and learning. With this purpose, a survey was used to analyse the perceptions of a sample of teachers $(\mathrm{N}=41)$ participating in the Project Experiment with Augmented Reality, supported by the Asturian Department of Education (2017-18), which involved 542 schoolchildren. Afterwards, at the end of the project, a SWOT analysis was made. Amongst the results, it can be highlighted that, according to the teachers' perception, AR increases scientific competences in students, as well as their motivation towards science. It also fosters collaboration and creates a classroom environment favourable for investigation and project based learning. However, some difficulties are detected, such as the limited training of teachers and the scarcity of technological resources in schools.

Keywords: Augmented reality, scientific contents, scientific competence, primary education.

Para citar este artículo: Villalustre, L., Del Moral, M.E. y Neira-Piñeiro, M. R. (2019). Percepción docente sobre la realidad aumentada en la enseñanza de Ciencias en Primaria. Análisis DAFO. Revista Eureka sobre Enseñanza y Divulgación de las Ciencias 16(3), 3201. doi: 10.25267/Rev_Eureka_ensen_divulg_cienc.2019.v16.i3.3301

\section{Introducción}

La enseñanza de las ciencias supone potenciar una constante interacción entre la realidad y el conocimiento, no sólo a través de la teoría sino también mediante la realización de experimentos que susciten la formulación de preguntas basadas en un razonamiento científico

\author{
Revista Eureka sobre Enseñanza y Divulgación de las Ciencias \\ Universidad de Cádi\%. APAC-Eureka. ISSN: 1697-011X \\ bttp:/ / dx.doi.org/10.25267/Rev_Eureka_ensen_divulg_cienc.2019.v16.i3.3301 \\ http:/ / reuredc.uca.es
}


(De Miguel 2006). Asimismo, implica plantear problemas, identificar diferentes caminos para resolverlos, desarrollar y observar experimentos sencillos, recoger datos, buscar y contrastar respuestas, etc. (Linn, Davis y Bell 2004). Evidentemente, desde una perspectiva didáctica, ello exige apostar por metodologías activas que contribuyan a impulsar la indagación en la escuela y rompan con las inercias denunciadas por Gil (2014), al constatar la prevalencia de modelos tradicionales al abordar contenidos relativos a hechos y conceptos científicos en 151 centros de Educación Primaria (España), siendo meramente referenciales los apoyados en propuestas metodológicas ligadas la investigación.

Las metodologías activas se caracterizan por la implicación de los discentes en el proceso de enseñanza-aprendizaje, contemplando tareas específicas que lo hagan posible y promoviendo actividades que requieran de su participación directa. En este sentido, Schroeder, Scott, Tolson, Huang y Lee (2007) establecen que las metodologías más efectivas para abordar contenidos científicos en la escuela son las basadas en la investigación y el trabajo colaborativo. De este modo, según apuntan Romero y Quesada (2014), la colaboración ofrece nuevas oportunidades para el aprendizaje científico ligadas a la promoción de la comunicación e interacción efectiva entre los sujetos -por ejemplo, para la resolución de problemas-, al activar tanto las habilidades sociales necesarias para relacionarse con los demás, como la capacidad de liderazgo, la búsqueda de consensos, etc.

Sin duda, se precisa contar con un clima de aula propicio que contribuya al desarrollo competencial del alumnado, tal y como apuntan Cornejo y Redondo (2001). Por ello, urge generar contextos de interacción que impulsen las habilidades de los estudiantes para la mediación, como mecanismo de contingencia para evitar conflictos, y para el desarrollo efectivo de un buen clima de aula (Savitz, Rowan y Fancsali 2015), propiciando situaciones idóneas que potencien la adquisición de nuevos aprendizajes relacionados con distintos contenidos científicos.

Además, la motivación de los estudiantes es una variable crítica para la enseñanza de las ciencias (Guisasola y Morentin 2007), pues se relaciona con las actitudes y expectativas que éstos poseen sobre las tareas a realizar y las metas a alcanzar, resultando factores clave que guían y dirigen su conducta, e influyen en los logros de aprendizaje. De ahí que el nivel de motivación se vincule con el tipo de estrategias de aprendizaje adoptadas, así como con los recursos tecnológicos utilizados para acercar la ciencia al alumnado. En este sentido, la realidad aumentada (RA) constituye un recurso disruptivo en la enseñanza de ciencias que ofrece numerosas oportunidades para potenciar la motivación e implicación de los estudiantes en el aprendizaje de las ciencias.

La RA transforma la percepción sensorial del mundo real, añadiendo creaciones de realidad virtual que generan modelos de realidad mixtos que superan las limitaciones de la representación física, al hacer perceptibles fenómenos y elementos complejos o abstractos (Villalustre y Del Moral 2017). Por ello, su utilización en la enseñanza de ciencias puede contribuir a favorecer su aprendizaje siempre que vaya ligada a la adopción de metodologías didácticas activas, próximas a la experimentación, que faciliten la asimilación y comprensión de conceptos científicos y generen actitudes positivas hacia la ciencia (González-Rogado, VivarQuintana y Elorza 2013; Stojanova, Kocaleva, Manevski, Kocev y Delipetrev 2015; ValverdeCrespo, Pro-Bueno y González-Sánchez 2018).

\section{Competencia científica y su activación con realidad aumentada}

Según Pedrinaci (2012) es preciso promover la comprensión de la ciencia y la tecnología entre los más jóvenes para prepararles para su vida futura. En ese mismo sentido, la OCDE (2006, p. 20) apuesta por una "formación científico-tecnológica que favorezca su participación en una 
sociedad donde la ciencia y la tecnología desempeñan un rol esencial”. Por ello, en el ámbito de la educación obligatoria, se intenta ofrecer una formación científica básica, acorde con las demandas de la sociedad actual, independientemente de las preferencias profesionales del alumnado hacia carreras de letras o ciencias en los niveles posteriores (Rebollo 2010).

En este contexto, y junto a la educación científica, surge el concepto de competencia científica, a menudo asociada a la matemática y tecnológica, como se recoge en el proyecto DeSeCo, la LOE y la LOMCE. Para Pedrinaci (2012), la competencia científica engloba las capacidades que ayudan al sujeto a aplicar el conocimiento científico para describir, explicar y predecir fenómenos naturales, comprender las peculiaridades de la ciencia; formular hipótesis y problemas, documentarse, argumentar e implicarse personal y, socialmente, tomar decisiones que afectan a su entorno natural. Por su parte, en las pruebas PISA (OCDE 2006) se enfatiza la capacidad del alumnado para aplicar los conocimientos científicos a la toma de decisiones relativas al medio natural, y, con posterioridad, se amplía el espectro de interacción a cuestiones científicas o relacionadas con la ciencia (OCDE 2016). Más tarde, se asume que esta competencia integra tanto conocimientos y capacidades como aspectos actitudinales, referidos al interés y disposición positiva de los sujetos hacia la ciencia (OCDE 2006 y 2017).

Para definir esta competencia y las dimensiones que la conforman se han propuesto diversos modelos (OCDE 2006 y 2017; Ministerio de Educación 2006 y 2007; Cañal 2012a y 2012b; Gobierno Vasco 2009; Junta de Andalucía 2007a y 2007b; Franco-Mariscal 2015; Rebollo 2010; etc.), que coinciden en considerarla integrada por conocimientos, habilidades y actitudes (Pedrinaci 2012). Además, todos ellos adoptan el enfoque competencial en la enseñanza de las ciencias, en un intento de renovar y mejorar la práctica pedagógica en este campo (FrancoMariscal 2015).

En este nuevo escenario de enseñanza-aprendizaje de ciencias, las Tecnologías de la Información y Comunicación (TIC) ofrecen herramientas de gran interés para promover el desarrollo de las diversas capacidades que integran la competencia científica. Cañal, GarcíaCarmona y Cruz-Guzmán (2016) consideran las TIC como recursos óptimos para promover la educación científica, que pueden integrarse en un modelo pedagógico basado en la indagación. Señalan que las tecnologías ofrecen múltiples posibilidades tanto para buscar información como para representar el conocimiento adquirido, registrar y organizar datos científicos, comunicar resultados y conclusiones, así como para simular fenómenos y procesos naturales de manera virtual. Además, Rojas (2017) señala que la adecuada integración de herramientas tecnológicas en el aula de ciencias no solo incrementa la motivación del alumnado y favorece el desarrollo de la competencia digital, sino que incide positivamente en el progreso de la competencia científica (Pérez Buendía 2014).

En particular, la RA puede considerarse una herramienta útil para activar la competencia científica en la enseñanza obligatoria, dado que permite añadir información virtual y superponerla a elementos del mundo físico o real, situando al estudiante en escenarios altamente interactivos, que enriquecen su percepción de la realidad y contribuyen a ampliar las experiencias de aprendizaje (Villalustre y Del Moral 2016a). Cawood y Fiala (2008) establecen diferentes niveles de RA:

- Nivel 0: Hiperenlaces en el mundo físico a través de códigos QR (Quick Response Barcode), que se activan desde cualquier dispositivo móvil.

- Nivel I: Realidad aumentada basada en marcadores, convirtiendo elementos en activadores mediante la superposición de modelos 3D.

- Nivel II: Realidad aumentada markerless; utilizando imágenes y objetos como activadores. 
- Nivel III: Visión aumentada con gafas específicas (ej. Google Project Glass) o lentillas biónicas.

Pese a ser una tecnología emergente, existen numerosas aplicaciones que se están implementando en los distintos cursos para introducir en las aulas los niveles de desarrollo de la RA que potencien la competencia científica (Villalustre y Del Moral, 2017). De igual modo, se han llevado a cabo diversas experiencias docentes innovadoras con RA, aplicadas en su mayoría al ámbito del aprendizaje científico. Así, González-Rogado, Vivar-Quintana y Elorza (2013) aproximan al alumnado al uso del laboratorio utilizando RA, mientras que Fracchia, Alonso y Martíns (2015) introducen este nuevo recurso en la enseñanza de las ciencias naturales en Educación Primaria logrando activar su motivación. Stojanova, Kocaleva, Manevski, Kocev y Delipetrev (2015) fomentan la conciencia medioambiental a través de RA, analizando el impacto de la acción humana, y Squire y Jan (2007) la utilizan en prácticas gamificadas para promover la investigación científica.

Solano, Casas y Guevara (2015) desarrollan una interesante experiencia con alumnos de $3^{\circ}$ de Primaria, basada en el uso de RA para aprender la clasificación de los seres vivos. Por su parte, la revisión efectuada por Cheng y Tsai (2013) da cuenta de los numerosos proyectos y experiencias innovadoras apoyadas en RA centrados en los diversos campos científicos (astronomía, biología, matemáticas, ciencias medioambientales, etc.) implementadas en distintos niveles educativos, cuyas actividades se relacionan con diferentes aprendizajes científicos, relativos tanto a la asimilación de conceptos como al desarrollo de destrezas.

Se ha podido constatar la existencia de infinidad de aplicaciones con RA diseñadas específicamente para favorecer el aprendizaje científico (Solano, Casas y Guevara 2015; Villalustre y Del Moral 2016b), muy útiles para abordar temas ligados a la ciencia en las diferentes etapas educativas, que permiten al alumnado acceder a contenidos científicos de manera lúdica e interactiva, propiciando la adquisición de nuevos conocimientos. En particular, y de acuerdo con diversas investigaciones (Fracchia, Alonso de Armiño y Martíns 2015; Solano, Casas y Guevara 2015; Villalustre y Del Moral 2017), la RA agrega información al mundo real y permite experimentar fenómenos o realidades naturales que difícilmente pueden ser observadas de otro modo, tales como visualizar representaciones tridimensionales del interior del cuerpo humano o del Universo. Esto contribuye a mejorar la comprensión de conceptos y procesos científicos, al recrear de manera virtual elementos o procesos naturales, haciéndolos visibles y accesibles para el alumnado en tiempo real. También les permite experimentar en contextos virtuales, favoreciendo el desarrollo de la competencia científica. Además, incrementa el interés de los menores y su motivación hacia las actividades mediadas con esta tecnología, lo que puede repercutir en una actitud positiva hacia la ciencia.

En este sentido, desde una perspectiva metodológica, la RA puede integrarse en el aula tanto para apoyar sesiones expositivas y favorecer la comprensión de conceptos, como para aplicarla a la experimentación y al desarrollo de actividades colaborativas (Fracchia, Alonso de Armiño y Martíns 2015), e, igualmente, puede impulsar el aprendizaje a través de la investigación (Cheng y Tsai 2013). Evidentemente, este recurso es compatible con la adopción de metodologías activas en el aula de ciencias, sin embargo la clave para que ello sea posible radica en la cualificación didáctico-tecnológica del profesorado.

El estudio de la RA aplicada a la Didáctica de las Ciencias es todavía muy reciente, y se precisan más evidencias científicas para profundizar en el conocimiento de los beneficios y posibilidades pedagógicas de esta tecnología. Con este propósito, la presente investigación muestra los resultados -a juicio del profesorado- derivados de la implementación de un proyecto con RA, desarrollado en aulas de ciencias con alumnado de Educación Primaria. 


\section{Percepción docente sobre la potencialidad de RA en la enseñanza de ciencias en primaria. Análisis DAFO.}

\section{Objetivos}

Se analizan las percepciones del profesorado sobre las posibilidades didácticas que ofrece la RA para favorecer el aprendizaje científico, tras participar en el proyecto Experiment with Augmented Reality (Exp-AR) desarrollado en Educación Primaria (2017-18). Concretamente, se estudian las referidas al desarrollo de competencias científicas, la implicación y motivación del alumnado, la colaboración de los estudiantes y el clima de aula generado. Asimismo, se identifican las debilidades, fortalezas, amenazas y oportunidades de la implementación de la RA en el aula de ciencias.

\section{Metodología}

La metodología adoptada posee un carácter mixto. En primer lugar, es cuantitativa, al constatar mediante un cuestionario diseñado ad hoc la percepción docente sobre las aportaciones de la RA para la adquisición y/o consolidación de conocimientos científicos y su repercusión en las actitudes del alumnado, tras participar en cualquiera de las 13 experiencias de integración de la RA desarrolladas en el mencionado proyecto. Para ello se toman como referencia investigaciones previas que analizan la percepción docente relativa a diferentes aspectos, tales como el desarrollo de competencias en el ámbito universitario (Gutiérrez, Pérez y Pérez 2011), la formación permanente del profesorado (García y Zubizarreta 2012), o la formación inicial y la competencia comunicativa (Chacón 2006), entre otras.

En segundo lugar, se adopta una metodología cualitativa, al efectuar un análisis interno, identificando las fortalezas y debilidades de la implementación curricular de la RA, y un análisis externo, para resaltar las oportunidades y amenazas que suscita, mediante una matriz DAFO (McNamara 1999). La investigación derivada de la implementación del proyecto constó de las siguientes fases (Figura 1):

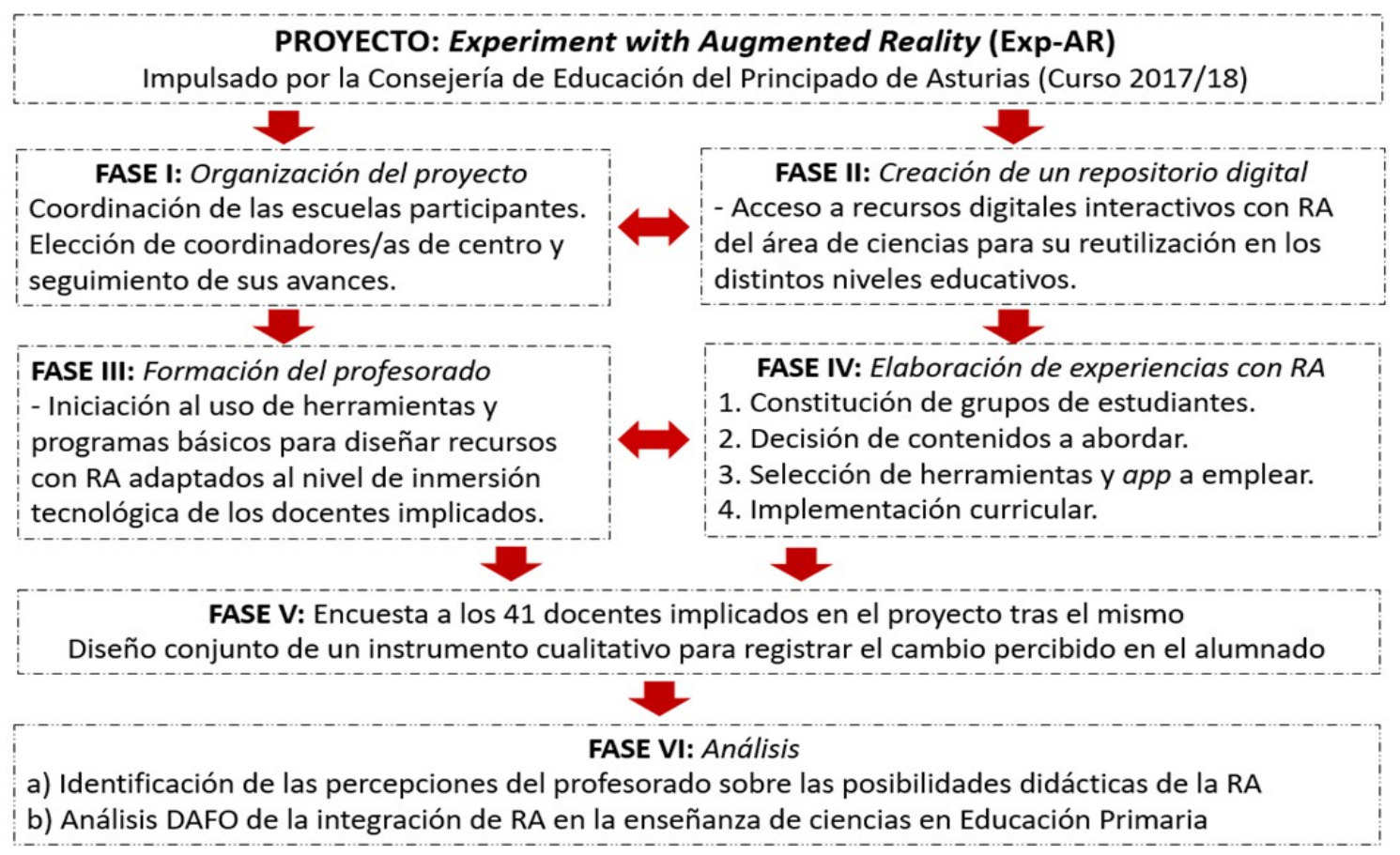

Figura 1. Fases que conformaron el Proyecto Exp-AR. Elaboración propia 


\section{Procedimiento}

Concluido el Proyecto Exp-AR, se enunciaron unos criterios comunes entre el profesorado y los investigadores para integrarlos en el cuestionario semi-abierto que, posteriormente, serviría para plasmar la percepción docente sobre el grado de activación observado en las competencias científicas, el nivel de implicación y motivación del alumnado en las experiencias desarrolladas con RA. También se registró su consideración respecto a la contribución de las mismas al fomento del trabajo colaborativo en el aula, y a la generación de un clima de aula proclive al aprendizaje. El tratamiento estadístico primó el análisis descriptivo, apoyándose en el SPSS (v.22).

Además, los 41 docentes y los investigadores universitarios implicados en el proyecto elaboraron una matriz DAFO, para efectuar el análisis interno del mismo, identificando las fortalezas y debilidades ofrecidas por esta tecnología para potenciar el aprendizaje de contenidos científicos en Primaria; y externo, mostrando las amenazas y oportunidades derivadas de la implementación de la RA en la enseñanza de las ciencias en este nivel.

\section{Instrumento}

El cuestionario integraba 32 ítems para registrar la percepción de los docentes sobre:

1) El cambio observado en las competencias científicas del alumnado, utilizando una escala tipo likert (nada, poco, bastante, mucho), identificando 28 indicadores, a partir de las aportaciones de Cañal (2012b) y de Franco-Mariscal (2015), agrupados en cinco dimensiones: comprensión del conocimiento científico, explicación de la realidad científica, evaluación y diseño de experimentos y preguntas científicas, interpretación de datos y pruebas científicas y actitud hacia la ciencia.

2) Los roles asumidos y nivel de implicación del alumnado (elección entre varias categorías).

3) La motivación del alumnado hacia los contenidos científicos, mediante una escala tipo likert (nada, poco, bastante, mucho).

4) Existencia (o no) de actividades colaborativas efectivas en el aula con RA.

5) Repercusión (o no) en el clima de trabajo de aula entre el alumnado.

\section{Contexto y muestra}

El proyecto Exp-AR, impulsado por la Consejería de Educación del Principado de Asturias, contó con la participación de 41 profesores y 542 alumnos de Educación Primaria (49\% niños y $51 \%$ niñas) procedentes de cinco colegios públicos de diferentes localidades del Principado de Asturias, quienes desarrollaron 13 experiencias centradas en la utilización de la RA para promover la adquisición y consolidación de aprendizajes sobre contenidos científicos (Tabla 1).

Para el 90\% del profesorado, ésta fue su primera aproximación a la RA. A pesar de que existen numerosas aplicaciones que abordan contenidos científicos haciendo uso de elementos 3D, los docentes se sintieron especialmente motivados e implicados para crear sus propios recursos aumentados. Para ello, adoptaron los niveles más básicos de RA, es decir, la elaboración de códigos QR y la utilización de láminas-marcadores prediseñadas para mostrar imágenes 3D (Quiver y Chromville), dada su facilidad de uso y las posibilidades didácticas que ofrecen para los cursos de primaria. 
Tabla 1. Breve descripción de las experiencias apoyadas en RA para abordar contenidos científicos. Elaboración propia.

\begin{tabular}{|c|c|c|c|}
\hline $\begin{array}{c}\text { Curso y objetivo de la } \\
\text { experiencia }\end{array}$ & $\begin{array}{c}\text { Metodología didáctica } \\
\text { adoptada }\end{array}$ & $\begin{array}{l}\text { Contenidos } \\
\text { abordados }\end{array}$ & $\begin{array}{c}\text { Uso de la Realidad } \\
\text { Aumentada }\end{array}$ \\
\hline $\begin{array}{l}1^{\mathrm{o}} \text { a } 6^{\circ} . \text { Comprender el } \\
\text { ciclo del agua y sus estados. }\end{array}$ & $\begin{array}{l}\text { Aprendizaje basado en } \\
\text { Proyectos (AbP) en } \\
\text { escuela rural: internivelar e } \\
\text { interdisciplinar. }\end{array}$ & $\begin{array}{l}\text { Ciclo del agua, } \\
\text { flotabilidad, } \\
\text { consumo } \\
\text { responsable. }\end{array}$ & $\begin{array}{l}\text { Programa HP Reveal y } \\
\text { Quiver-ed para crear recursos } \\
\text { multimedia e interactivos. }\end{array}$ \\
\hline $\begin{array}{l}1^{\circ} \text { y } 2^{\circ} \text {. Identificar los } \\
\text { rasgos de los animales } \\
\text { vertebrados e } \\
\text { invertebrados. }\end{array}$ & $\begin{array}{l}\text { Apoyo a la metodología } \\
\text { tradicional. }\end{array}$ & $\begin{array}{l}\text { Animales } \\
\text { vertebrados e } \\
\text { invertebrados. }\end{array}$ & $\begin{array}{l}\text { Utilización de Códigos QR } \\
\text { para ampliar información. } \\
\text { Láminas Chromville Science. }\end{array}$ \\
\hline $\begin{array}{l}2^{\circ} \text {. Conocer el proceso de } \\
\text { elaboración de la } \\
\text { mantequilla. }\end{array}$ & $\begin{array}{l}\text { AbP en el aula bilingüe. } \\
\text { AICLE. }\end{array}$ & $\begin{array}{l}\text { Proceso químico } \\
\text { en la elaboración } \\
\text { de la mantequilla. }\end{array}$ & $\begin{array}{l}\text { Diseño de Códigos QR con } \\
\text { enlaces a vídeos que } \\
\text { explican su elaboración. }\end{array}$ \\
\hline $\begin{array}{l}3^{\circ} . \text { Analizar el ciclo del } \\
\text { agua }\end{array}$ & $\begin{array}{l}\text { Apoyo a la metodología } \\
\text { tradicional. }\end{array}$ & $\begin{array}{l}\text { Fases y proceso } \\
\text { del ciclo del agua. }\end{array}$ & $\begin{array}{l}\text { Utilización de Códigos QR } \\
\text { para ampliar información. }\end{array}$ \\
\hline $\begin{array}{l}3^{\circ} . \text { Analizar los elementos } \\
\text { que intervienen en el } \\
\text { magnetismo. }\end{array}$ & $\begin{array}{l}\text { AbP y experimentación en } \\
\text { el aula bilingüe. AICLE. }\end{array}$ & $\begin{array}{l}\text { Magnetismos: } \\
\text { explicación y } \\
\text { funcionamiento. }\end{array}$ & $\begin{array}{l}\text { Diseño de Códigos QR por } \\
\text { parte de los alumnos para la } \\
\text { creación de un mural. }\end{array}$ \\
\hline $\begin{array}{l}4^{\circ} . \text { Conocer los árboles y } \\
\text { arbustos del colegio. }\end{array}$ & $\begin{array}{l}\text { AbP para la creación de } \\
\text { itinerarios. }\end{array}$ & $\begin{array}{l}\text { Flora del entorno } \\
\text { próximo al colegio }\end{array}$ & $\begin{array}{l}\text { Integración de Códigos QR } \\
\text { en itinerarios interactivos } \\
\text { por parte de los alumnos. }\end{array}$ \\
\hline $\begin{array}{l}5^{\circ} . \text { Identificar la flora de la } \\
\text { región. }\end{array}$ & $\begin{array}{l}\text { Apoyo a la metodología } \\
\text { tradicional en el aula } \\
\text { bilingüe. AICLE. }\end{array}$ & Flora de la región. & $\begin{array}{l}\text { Utilización de Códigos QR } \\
\text { para ampliar información } \\
\text { sobre la flora del entorno. }\end{array}$ \\
\hline $\begin{array}{l}5^{\circ} \text {. Analizar la flora y } \\
\text { fauna del Parque Isabel la } \\
\text { Católica (Gijón). }\end{array}$ & $\begin{array}{l}\text { AbP para la creación de } \\
\text { itinerarios. }\end{array}$ & $\begin{array}{l}\text { Flora y fauna del } \\
\text { parque. }\end{array}$ & $\begin{array}{l}\text { Diseño de Códigos QR por } \\
\text { parte de los alumnos para } \\
\text { crear itinerarios. } \\
\text { Láminas Chromville Science. }\end{array}$ \\
\hline $\begin{array}{l}5^{\circ} . \text { Conocer cómo } \\
\text { funcionan las redes de } \\
\text { comunicación. }\end{array}$ & $\begin{array}{l}\text { AbP en el aula bilingüe. } \\
\text { AICLE. }\end{array}$ & $\begin{array}{l}\text { Bases de las redes } \\
\text { de comunicación. }\end{array}$ & $\begin{array}{l}\text { Creación de recursos con } \\
\text { Códigos QR y HP Reveal. }\end{array}$ \\
\hline $\begin{array}{l}5^{\circ} . \text { Identificar y conocer las } \\
\text { máquinas del centro. }\end{array}$ & $\begin{array}{l}\text { AbP y experimentación en } \\
\text { el aula bilingüe. AICLE }\end{array}$ & $\begin{array}{l}\text { Máquinas del } \\
\text { centro. }\end{array}$ & $\begin{array}{l}\text { Diseño de Códigos QR por } \\
\text { parte del alumnado para } \\
\text { elaborar materiales. }\end{array}$ \\
\hline $\begin{array}{l}5^{\circ} . \text { Distinguir las diferentes } \\
\text { etapas de la historia. }\end{array}$ & $\mathrm{AbP}$ & $\begin{array}{l}\text { Etapas: } \\
\text { Prehistoria, Edad } \\
\text { Antigua y Media. }\end{array}$ & $\begin{array}{l}\text { Elaboración de Códigos } \\
\text { QR para ampliar y } \\
\text { completar la información. }\end{array}$ \\
\hline $\begin{array}{l}6^{\circ} . \text { Reconocer las plantas y } \\
\text { pájaros de la localidad. }\end{array}$ & AbP para crear itinerarios & $\begin{array}{l}\text { Flora y fauna del } \\
\text { entorno inmediato }\end{array}$ & $\begin{array}{l}\text { Diseño de Códigos QR por } \\
\text { parte de los alumnos para } \\
\text { crear itinerarios. } \\
\text { Láminas Chromville Science. }\end{array}$ \\
\hline $\begin{array}{l}6^{\circ} . \text { Diseñar experimentos } \\
\text { ligados a la electricidad y el } \\
\text { magnetismo. }\end{array}$ & $\mathrm{AbP}$ & $\begin{array}{l}\text { Electricidad y } \\
\text { magnetismo. }\end{array}$ & $\begin{array}{l}\text { Creación de Códigos QR } \\
\text { ligados a vídeos e imágenes } \\
\text { de los experimentos. }\end{array}$ \\
\hline
\end{tabular}




\section{Experiencias desarrolladas con RA para abordar contenidos científicos}

En la tabla 1 se recogen las experiencias llevadas a cabo por el profesorado de Educación Primaria en el marco del proyecto, pero a continuación se describen dos de ellas con el propósito de ofrecer una visión más cercana al modo en que se abordaron los contenidos científicos utilizando recursos de RA. Así, en la propuesta Arboles y arbustos del entorno del colegio el alumnado de $4^{\circ}$ de primaria utilizó códigos QR para conocer e indagar sobre la flora del entorno próximo al colegio, elaborando diferentes itinerarios didácticos. La información encontrada sobre las características de la flora de su entorno -vídeos, imágenes, gráficos, etc.se vinculó a los códigos QR que colgaron en cada los árboles y arbustos del recinto próximo al colegio. Con ello, crearon itinerarios para que todo el alumnado del centro pudiera acceder a la información. Simultáneamente, elaboraron un mural (Figura 2) que ubicaron en el pasillo del colegio, donde expusieron fotografías de los árboles y plantas junto con el código QR asociado, para afianzar los contenidos abordados.

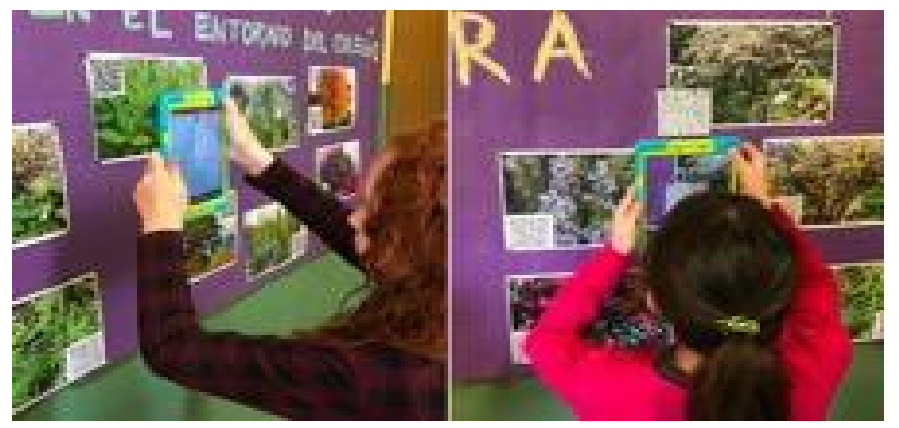

Figura 2. Mural creado por alumnado de $4^{\circ}$ de Primaria, donde se utilizan códigos QR para conocer la flora del entorno.

De igual modo, el alumnado de un Colegio Rural Agrupado (CRA) utilizó diferentes herramientas de RA para crear un Lapbook sobre el ciclo del agua, tales como los programas $H p$ Reveal, Quiver-ed y editores de Códigos QR, para profundizar en el conocimiento de las fases del ciclo del agua, la flotabibilidad y la importancia del consumo responsable del agua (Figura 3). El trabajo de diseño del lapbook permitió el trabajo colaborativo de los estudiantes para incorporar recursos de RA, que permitían superponer información a través de vídeos y animaciones que ejemplificaban cada parte del ciclo del agua. Además, grabaron vídeos de concienciación frente a la sequía, donde exponían los argumentos para efectuar un uso responsable del agua, que incorporaron al lapbook mediante códigos QR y con la aplicación HP Reveal.

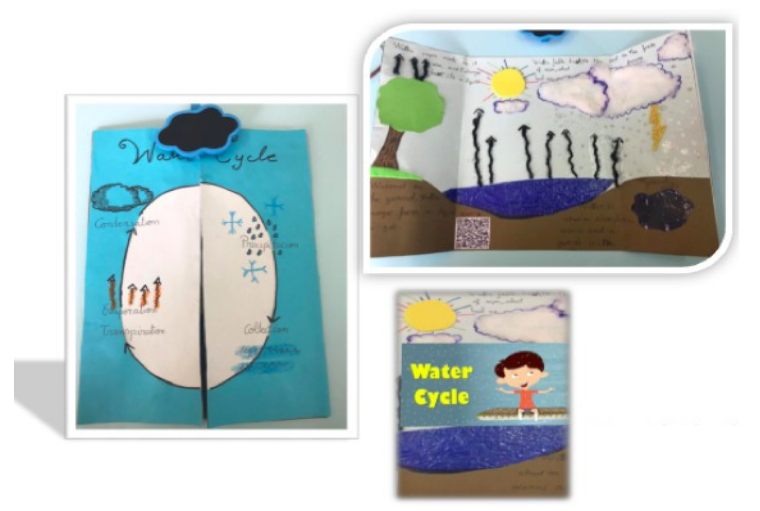

Figura 3. Lapbook con realidad aumentada elaborado por el alumnado de Primaria 
Por otro lado, y además de los recursos ya comentados (QR y HP Reveal), en varias de las experiencias se emplearon láminas-marcadores prediseñadas de Quiver y Chromville Science para abordar temáticas relacionadas con los diferentes proyectos. Estas láminas, previamente coloreadas por el alumnado, permitieron la generación de elementos 3D y la interacción lúdica con las imágenes de realidad aumentada, favoreciendo el aprendizaje sobre diferentes contenidos científicos. Por ejemplo, estos recursos sirvieron para adquirir aprendizajes básicos sobre el cuidado de las plantas y sobre el proceso de metamorfosis de la rana (Figura 4).
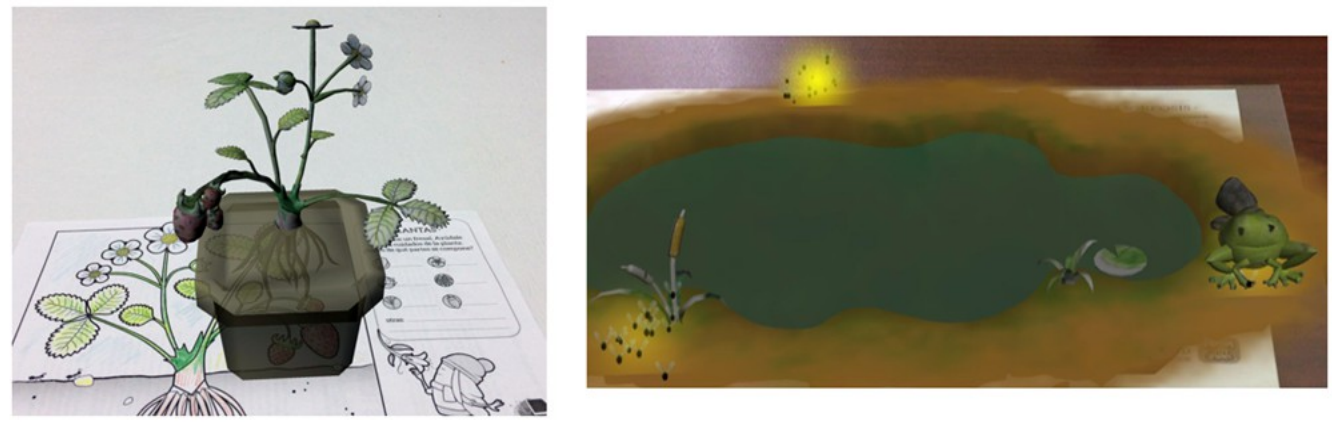

Figura 4. Elementos 3D generados a partir de láminas-marcadores de Quiver y Chromville Science

\section{Resultados}

\section{Percepción docente tras concluir las experiencias con RA}

Una de las variables críticas que contribuyen a afianzar la participación de los docentes en proyectos innovadores con TIC en las escuelas está relacionada con su percepción sobre su utilidad, al constatar un incremento tanto de la implicación y motivación del alumnado como del logro de aprendizajes y competencias de diversa índole tras su implementación (Del Moral, Villalustre y Neira-Piñeiro 2014). En ese sentido, se quiso indagar al respecto preguntándoles sobre el cambio observado en las competencias cientificas alcanzadas por el alumnado, tras el proyecto, y en su motivación y grado de implicación en las experiencias cientificas desarrolladas, colaboración mutua y sobre el clima de aula generado. A continuación, se exponen los resultados alcanzados a su juicio.

\section{Competencias cientificas desarrolladas}

El diseño de actividades, ligado a la selección de contenidos científicos a abordar, junto a las herramientas digitales utilizadas y el tipo de aplicación de RA adoptada por los docentes en cada curso, pretendían propiciar la adquisición y desarrollo de determinadas competencias científicas. De ahí que al preguntarles por su percepción sobre el grado de desarrollo propiciado en el alumnado, se muestran, en general, bastante satisfechos. Los mayores cambios percibidos se refieren a la capacidad del alumnado para comprender y asimilar conceptos como el reconocimiento y análisis de elementos del entorno natural y social $(22,5 \%)$, así como para utilizar términos científicos, símbolos, unidades de magnitudes y escalas $(17,3 \%)$. Consideran que la RA, en general, ha contribuido a minimizar el grado de complejidad y abstracción de algunos procesos científicos como el ciclo del agua, la electricidad y el magnetismo (Tabla 2). El 19\% afirma que estas experiencias han activado bastante la capacidad del alumnado para relacionar conocimientos científicos básicos entre sí como la producción de la mantequilla, el funcionamiento de máquinas (alarmas, altavoces, etc.), y un $12,5 \%$ percibe que la RA ha facilitado detectar semejanzas y diferencias entre fenómenos científicos, como la fase de ebullición o congelación del agua, discriminar animales vertebrados e invertebrados, etc. 
Tabla 2. Percepción docente sobre el cambio suscitado en las competencias del alumnado relativas a la comprensión de conceptos o procesos científicos, concluido el proyecto. Elaboración propia.

\begin{tabular}{|l|c|c|c|c|}
\hline $\begin{array}{l}\text { Comprensión de conceptos o procesos científicos } \\
\text { (CCPC) }\end{array}$ & Nada & Poco & Bastante & Mucho \\
\hline $\begin{array}{l}\text { Reconoce y analiza elementos del entorno natural y } \\
\text { social }\end{array}$ & 0,0 & 0,0 & 22,5 & 2,5 \\
\hline Explica gráficamente conceptos científicos & 0,0 & 0,0 & 12,5 & 2,0 \\
\hline $\begin{array}{l}\text { Identifica las semejanzas y diferencias entre fenómenos } \\
\text { científicos }\end{array}$ & 0,0 & 0,0 & 14,2 & 3,0 \\
\hline $\begin{array}{l}\text { Relaciona entre sí diferentes conocimientos científicos } \\
\text { básicos. }\end{array}$ & 0,0 & 0,0 & 19,0 & 3,5 \\
\hline $\begin{array}{l}\text { Reconoce y utiliza términos científicos, símbolos, } \\
\text { unidades de magnitudes, escalas. }\end{array}$ & 0,0 & 0,0 & 17,3 & 3,5 \\
\hline TOTAL CCPC & $\mathbf{0 , 0}$ & $\mathbf{0 , 0}$ & $\mathbf{8 5 , 5}$ & $\mathbf{1 4 , 5}$ \\
\hline
\end{tabular}

De modo similar, el 22\% del profesorado percibe que la RA ha impulsado bastante la capacidad del alumnado para describir y observar objetos y fenómenos científicos, y un 15\% matiza que ha favorecido su habilidad para explicar fenómenos o hechos como el funcionamiento de las redes de comunicación o máquinas sencillas, la temperatura de ebullición y congelación del agua, etc., argumentando con coherencia sus predicciones. Asimismo, ven que el 5,2\% del alumnado desarrolló mucho su capacidad para formular correctamente hipótesis sencillas y razonadas, por ejemplo sobre electricidad (Tabla 3).

Tabla 3. Percepción docente sobre el cambio suscitado en las competencias del alumnado relativas a la explicación de la realidad o hechos científicos, concluido el proyecto. Elaboración propia.

\begin{tabular}{|l|c|c|c|c|}
\hline $\begin{array}{l}\text { Explicación de la realidad o hechos científicos } \\
\text { (ERHC) }\end{array}$ & Nada & Poco & Bastante & Mucho \\
\hline Describe objetos y fenómenos científicos observados. & 0,0 & 1,6 & 22,0 & 2,9 \\
\hline Formula hipótesis razonadas sencillas. & 0,0 & 1,4 & 14,5 & 5,2 \\
\hline $\begin{array}{l}\text { Utiliza conceptos y modelos científicos para analizar } \\
\text { situaciones o problemas. }\end{array}$ & 0,0 & 1,0 & 13,0 & 2,0 \\
\hline Argumenta coherentemente sus predicciones. & 0,0 & 1,4 & 15,5 & 4,0 \\
\hline $\begin{array}{l}\text { Comprende y explica las diferentes fases de un } \\
\text { proceso. }\end{array}$ & 0,0 & 1,0 & 13,0 & 3,5 \\
\hline TOTAL ERHC & $\mathbf{0 , 0}$ & $\mathbf{6 , 4}$ & $\mathbf{7 6 , 0}$ & $\mathbf{1 7 , 6}$ \\
\hline
\end{tabular}

Sin embargo, los docentes resaltan que la competencia para diseñar experimentos y formular cuestiones se vio potenciada poco $(31,2 \%)$ con la RA (Tabla 4). Perciben que se incrementaron poco las tareas de documentación para realizar pequeñas investigaciones o experimentos $(8,7 \%)$, así como para obtener conclusiones razonadas a partir de la observación y/o experimentación (6,3\%). No obstante, el 26,8\% del profesorado considera que los discentes utilizaron bastante las TIC para llevar a cabo diferentes tareas relacionadas con la ciencia, puesto que tuvieron que manejar dispositivos móviles y programas para generar y leer códigos $\mathrm{QR}$, interactuar con juegos online, acceder a simuladores elementales, etc. 
Tabla 4. Percepción docente sobre el cambio suscitado en las competencias del alumnado relativas al diseño de experimentos y preguntas científicas, concluido el proyecto. Elaboración propia.

\begin{tabular}{|l|c|c|c|c|}
\hline $\begin{array}{l}\text { Diseño de experimentos y preguntas científicas } \\
\text { (DEPC) }\end{array}$ & Nada & Poco & Bastante & Mucho \\
\hline $\begin{array}{l}\text { Obtiene conclusiones razonadas a partir de la } \\
\text { observación y/o experimentación. }\end{array}$ & 0,0 & 6,3 & 13,7 & 0,0 \\
\hline $\begin{array}{l}\text { Busca pruebas que confirmen o refuten teorías o } \\
\text { hipótesis. }\end{array}$ & 0,0 & 5,7 & 7,2 & 0,0 \\
\hline $\begin{array}{l}\text { Elabora tablas, diagramas, gráficas, mapas, imágenes } \\
\text { en 3D, dibujos, esquemas, etc. para representar datos o } \\
\text { elementos de la realidad. }\end{array}$ & 0,0 & 6,0 & 9,3 & 0,0 \\
\hline $\begin{array}{l}\text { Se documenta para realizar pequeñas investigaciones o } \\
\text { experimentos. }\end{array}$ & 0,0 & 8,7 & 11,8 & 0,0 \\
\hline Utiliza las TIC para tareas relacionadas con la ciencia. & 0,0 & 4,5 & 26,8 & 0,0 \\
\hline TOTAL DEPC & $\mathbf{0 , 0}$ & $\mathbf{3 1 , 2}$ & $\mathbf{6 8 , 8}$ & $\mathbf{0 , 0}$ \\
\hline
\end{tabular}

De modo semejante, la competencia para interpretar datos derivados de pruebas científicas se activó bastante para el 50\% del profesorado, mientras un 37,4\% señala que fue poco (Tabla 5). Ello dependía del tipo de actividad propuesta, pues con los mayores se pudieron medir temperaturas para hacer helados con agua, calibrar el tiempo de batido de la nata y elaborar mantequilla, etc. El 9\% reconoce que la identificación de fuentes de información fiable fue limitada en los escolares, y el $8 \%$ señala que dudaban al distinguir entre la mera opinión y la evidencia basada en pruebas, puesto que ello implicaba destrezas cognitivas de orden superior, dado que por su edad todavía no saben identificar fuentes de datos fiables, utilizando solamente la Wikipedia. No obstante, el 14\% percibe que el alumnado desarrolló bastante la habilidad para extraer e interpretar información de imágenes 3D, fotografías, dibujos, esquemas, mapas, etc. extraídas de internet.

Tabla 5. Percepción docente sobre el cambio suscitado en las competencias del alumnado relativas a la interpretación de datos y pruebas científicas, concluido el proyecto. Elaboración propia.

\begin{tabular}{|l|c|c|c|c|}
\hline Interpretación de datos y pruebas científicas (IDPC) & Nada & Poco & Bastante & Mucho \\
\hline Reconoce fuentes de información fiables. & 0,0 & 9,0 & 5,0 & 2,5 \\
\hline $\begin{array}{l}\text { Extrae e interpreta información de imágenes 3D, fotografías, } \\
\text { dibujos, esquemas, mapas, etc. }\end{array}$ & 0,0 & 5,4 & 14,0 & 1,0 \\
\hline $\begin{array}{l}\text { Compara, contrasta y clasifica información procedente de } \\
\text { varias fuentes. }\end{array}$ & 0,0 & 7,5 & 8,5 & 3,6 \\
\hline $\begin{array}{l}\text { Distingue entre la mera opinión y la evidencia basada en } \\
\text { pruebas concretas. }\end{array}$ & 0,0 & 8,0 & 12,5 & 3,0 \\
\hline $\begin{array}{l}\text { Reflexiona sobre las implicaciones sociales de los avances } \\
\text { científicos y tecnológicos }\end{array}$ & 0,0 & 7,5 & 10,0 & 2,5 \\
\hline TOTAL IDPC & $\mathbf{0 , 0}$ & $\mathbf{3 7 , 4}$ & $\mathbf{5 0 , 0}$ & $\mathbf{1 2 , 6}$ \\
\hline
\end{tabular}


Sin embargo, el sentir generalizado del profesorado sobre la contribución de las actividades apoyadas en RA es unánime, pues coinciden en que han ayudado mucho a generar unas actitudes positivas hacia la ciencia $(62,8 \%)$ o bastante $(37,2 \%)$, por ejemplo, al vincular códigos QR con vídeos sobre el nacimiento de animales mamíferos u ovíparos, etc., o al colorear e interaccionar con láminas-marcadores que puedan simular el crecimiento de plantas al regarlas y abonarlas, o recrear la metamorfosis de una rana o mariposa, etc. (Tabla 6). Concretamente, destacan el cuidado del medioambiente $(9,7 \%)$, la responsabilidad para reciclar $(9,8 \%)$, y el gusto por querer profundizar en temas científicos $(8,7 \%)$, ligado por ejemplo, a ver a través del microscopio las células de las hojas -previamente recogidas en el parque-, observar cómo se disuelven en agua distintas sustancias, o cómo cristalizan soluciones salinas, etc.

Tabla 6. Percepción docente sobre el cambio suscitado en las competencias del alumnado relativas a la actitud y gusto por el aprendizaje de la ciencia, concluido el proyecto. Elaboración propia.

\begin{tabular}{|l|c|c|c|c|}
\hline $\begin{array}{l}\text { Actitud positiva y gusto por el aprendizaje de la ciencia } \\
\text { (APGAC) }\end{array}$ & Nada & Poco & Bastante & Mucho \\
\hline $\begin{array}{l}\text { Muestra interés por cuestiones medioambientales y/o } \\
\text { problemas científicos. }\end{array}$ & 0,0 & 0,0 & 5,2 & 9,7 \\
\hline Cuestiona los hechos científicos. & 0,0 & 0,0 & 3,6 & 7,6 \\
\hline $\begin{array}{l}\text { Posee conciencia sobre la necesidad de cooperar y asume } \\
\text { responsabilidades en temáticas científicas. }\end{array}$ & 0,0 & 0,0 & 5,7 & 9,0 \\
\hline Alienta planes y toma de decisiones sobre temas científicos. & 0,0 & 0,0 & 2,0 & 4,8 \\
\hline Fomenta respuestas válidas a problemas científicos. & 0,0 & 0,0 & 4,3 & 5,2 \\
\hline $\begin{array}{l}\text { Se responsabiliza de la repercusión de las propias acciones en } \\
\text { el impacto medioambiental. }\end{array}$ & 0,0 & 0,0 & 5,3 & 9,8 \\
\hline Considera útil para la vida lo aprendido en ciencias. & 0,0 & 0,0 & 2,5 & 7,4 \\
\hline Despierta el gusto por la ciencia y por profesiones afines. & 0,0 & 0,0 & 4,6 & 8,7 \\
\hline TOTAL APGAC & $\mathbf{0 , 0}$ & $\mathbf{0 , 0}$ & $\mathbf{3 7 , 2}$ & $\mathbf{6 2 , 8}$ \\
\hline
\end{tabular}

Motivación e implicación del alumnado en las experiencias cientificas

Así pues, la motivación del alumnado, según los docentes, queda reflejada en su apertura y solicitud de nuevas actividades apoyadas en el uso de RA. En la figura 5 se evidencia que el $78 \%$ del profesorado cree que el interés suscitado por estas experiencias ha sido máximo, junto al $22 \%$ que considera que ha contribuido bastante a estimular al alumnado a profundizar en los contenidos científicos abordados, como los identificados en la tabla 1.

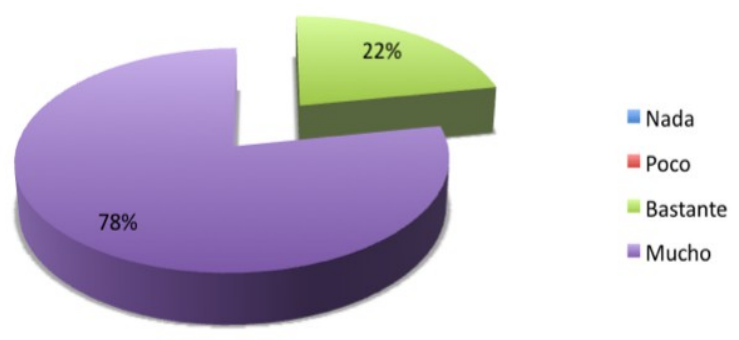

Figura 5. Percepción docente sobre el grado de motivación del alumnado hacia las experiencias con RA. Elaboración propia. 
Además, esta pregunta permitía a los docentes argumentar libremente su respuesta, por lo que se apuntan algunas de las apreciaciones más representativas:

«Se observa un alto grado de implicación y orgullo por la tarea realizada, como la vinculación de códigos QR con información multimedia complementaria a los temas abordados» (PROF1).

«Reclaman más actividades similares con RA, especialmente relacionadas con la simulación de procesos a través de la interacción con láminas-marcadores (metamorfosis de la rana, mariposa, etc.)» (PROF2).

«Favorece el proceso autónomo de aprendizaje, los alumnos no se muestran pasivos en ningún momento, sino que, se activan positivamente, es decir, participan de modo tranquilo durante la actividad, sin dejar de trabajar, y se consiguen los objetivos propuestos de forma cooperativa. Cada paso superado les refuerza para la siguiente búsqueda» (PROF3).

«Su motivación se refleja en la participación y grado de implicación en el proyecto, tienen más ganas de trabajar. Desean terminar el proyecto para ver el resultado global, mostrando iniciativa e interés por la actividad» (PROF4).

Más concretamente, se solicitó al profesorado que indicara el nivel de implicación de los estudiantes en las actividades desarrolladas, para poder tipificar los roles asignados a éstos. La Tabla 7 muestra que un 54,3\% exploraba e interactuaba con las aplicaciones RA seleccionadas, y un $45,7 \%$ participaba en el diseño y producción de recursos, principalmente mediante la creación de códigos QR. De ello se infiere la predominancia en el alumnado de roles de explorador activo y creador de recursos, alejados del de mero consumidor.

Tabla 7. Percepción docente sobre la implicación del alumnado en las experiencias desarrolladas con RA. Elaboración propia.

\begin{tabular}{|l|l|}
\hline Niveles de implicación & Porcentajes \\
\hline Observaron lo que se les presentaba. & 0,0 \\
\hline Exploraron e interaccionaron con los recursos proporcionados. & 54,3 \\
\hline Buscaron otras aplicaciones de RA de forma autónoma. & 0,0 \\
\hline Participaron en el diseño y producción de recursos con RA. & 45,7 \\
\hline
\end{tabular}

Colaboración entre el alumnado y clima de aula generado

Por otro lado, al preguntar a los docentes si estiman que las experiencias desarrolladas con RA favorecieron el trabajo colaborativo del alumnado, el 93,4\% lo afirma rotundamente, matizando sus estrategias para acometer y distribuir las distintas tareas, aquí se recogen las más representativas:

«Organizamos la actividad de diseño de códigos QR para vincular recursos propios con información multimedia (vídeos, canciones, animaciones, etc.), en pequeños grupos, con reparto de tareas y trabajo en común» (PROF5).

«Se trabaja en grupos de dos o tres alumnos para la búsqueda de información y la resolución de las actividades. Esos grupos se van cambiando para cada cuestionario, e incluso dentro del mismo, en varios días. De modo que, los alumnos que terminan una parte ayudan a los que han tardado más en encontrar la información» (PROF6). «El uso de diversos programas (generador códigos QR, blog, reductor direcciones web, powerpoint, etc.) generó una dinámica de apoyo entre el alumnado, ayudándose en su realización» (PROF7). 
«Se formaron grupos heterogéneos integrados por cuatro alumnos/as que se repartían la tarea para conseguir el objetivo marcado. Interactuaban conjuntamente y se ayudaban mutuamente» (PROF8).

Finalmente, hay que reseñar que el 70,8\% del profesorado percibe que estas actividades han contribuido a la mejora del clima de aula, disminuyendo las conductas disruptivas al captar la atención del conjunto del alumnado. Otros argumentos que aducen a favor de estas experiencias apoyadas en RA, inciden en que:

«Generan espacios de aprendizaje colectivo mediante técnicas de trabajo colaborativo que implican el diálogo y la toma de decisiones conjuntas» (PROF9).

«Se trabaja con compañeros diferentes, durante varios días, compartiendo trabajo con una gran parte de la clase. El ambiente es tranquilo, a pesar de que la actividad requiere salir y entrar del aula constantemente en distintos momentos y de forma autónoma -para recoger hojas o colocar códigos QR en los árboles del jardín-, trabajan muy bien y muy motivados» (PROF10).

«Se apoyan y se ayudan sin importar el tiempo que necesitan para que su/s compañero/s terminen» PROF11)

«El alumnado estuvo muy motivado por la actividad con lo que no dio lugar a conductas disruptivas» (PROF12).

«El trabajar en equipo y el sentirse todos importantes y valorados ha favorecido la integración del alumnado que presenta más problemas» (PROF13).

\section{Análisis DAFO}

Tras culminar las experiencias y recabar datos sobre la percepción del profesorado respecto a su ejecución, y con el apoyo del juicio de expertos, se procedió al análisis y reflexión de los resultados obtenidos, identificando las fortalezas y debilidades, así como las amenazas y oportunidades que estos nuevos recursos tecnológicos ofrecen para la enseñanza de las ciencias.

\section{Fortalezas y debilidades detectadas}

A continuación, se recoge la valoración de los factores internos que han favorecido o condicionado el desarrollo de nuevas experiencias formativas centradas en la utilización de la RA como recurso disruptivo para abordar contenidos científicos en Primaria (Tabla 8):

Tabla 8. Análisis DAFO: fortalezas y debilidades que ofrece la RA para potenciar el aprendizaje de contenidos científicos en Primaria (análisis interno). Elaboración propia.

\begin{tabular}{|c|c|}
\hline Fortalezas, vinculadas a: & Debilidades, asociadas a: \\
\hline $\begin{array}{l}\text { a) Potencialidades didácticas en el área de ciencias } \\
\text { - Posibilita la experimentación dirigida o guiada. } \\
\text { - Contribuye positiva y significativamente a activar } \\
\text { dinámicas de aprendizaje activo y por descubrimiento. } \\
\text { - Facilita la presentación o puesta en común de tareas. } \\
\text { - Promueve aprendizajes ligados al medio natural. } \\
\text { - Favorece la comprensión de procesos complejos. } \\
\text { b) Competencias científicas más activadas } \\
\text { - Tareas de investigación científica básica: búsqueda, } \\
\text { tratamiento y difusión de información. } \\
\text { - Conciencia medioambiental y/o respeto a los } \\
\text { animales. } \\
\text { - Comprensión del conocimiento y realidad científica. } \\
\text { - Actitud positiva hacia la ciencia. }\end{array}$ & $\begin{array}{l}\text { a) Limitaciones para la enseñanza de ciencias } \\
\text { - Escasa dotación de dispositivos móviles que } \\
\text { ralentizan la utilización de la RA en ciencias. } \\
\text { - Exige conocimientos básicos previos al } \\
\text { profesorado, para diseñar propuestas efectivas. } \\
\text { - Reducido tiempo para implementar innovaciones } \\
\text { con RA dentro del horario escolar. } \\
\text { b) Competencias científicas menos activadas } \\
\text { - Diseño de experimentos y preguntas científicas. } \\
\text { - Interpretación de datos y pruebas científicas. } \\
\text { - Distinción entre la mera opinión y la evidencia } \\
\text { basada en pruebas concretas. } \\
\text { - Identificación de fuentes de información fiables. }\end{array}$ \\
\hline
\end{tabular}


Tabla 8: Continuación

\begin{tabular}{|c|c|}
\hline Fortalezas, vinculadas a: & Debilidades, asociadas a: \\
\hline $\begin{array}{l}\text { c) Motivación e implicación del alumnado } \\
\text { - Estimula su motivación hacia temáticas científicas. } \\
\text { - Potencia su implicación e interés, incrementando el } \\
\text { aprovechamiento. } \\
\text { d) Trabajo colaborativo } \\
\text { - Fomenta la realización de tareas grupales entre el } \\
\text { alumnado. } \\
\text { - Propicia la colaboración entre el profesorado para } \\
\text { crear recursos y enriquecer el proceso de E-A. } \\
\text { e) Clima de aula } \\
\text { - Se mejora, resultado de las dinámicas colaborativas } \\
\text { puestas en juego al diseñar actividades con carácter } \\
\text { lúdico con los nuevos recursos. }\end{array}$ & $\begin{array}{l}\text { c) Motivación e implicación del alumnado } \\
\text { - Sin una correcta planificación didáctica, su } \\
\text { motivación e implicación desaparece con la } \\
\text { novedad de los recursos RA utilizados. } \\
\text { d) Trabajo colaborativo } \\
\text { - La ratio elevada de alumnos por aula dificulta el } \\
\text { desarrollo de tareas colaborativas. } \\
\text { - Poca implicación del profesorado, lo que } \\
\text { ralentiza la ejecución de proyectos colaborativos. } \\
\text { e) Clima de aula } \\
\text { - La escasez de recursos tecnológicos genera } \\
\text { situaciones críticas para determinar quién accede a } \\
\text { ellos y los manipula. }\end{array}$ \\
\hline
\end{tabular}

\section{Oportunidades y amenazas identificadas}

Asimismo, en la Tabla 9 se plasma el análisis externo de las oportunidades y amenazas derivadas de la implementación de la RA en el aula de ciencias de Educación Primaria.

Tabla 9. Análisis DAFO: oportunidades y amenazas del uso de RA en ciencias en Primaria (análisis externo). Elaboración propia.

\begin{tabular}{|c|c|}
\hline Oportunidades & Amenazas \\
\hline $\begin{array}{l}\text { Innovaciones con } \mathrm{R} A \text { en el área de ciencias } \\
\text { - Potencian la competencia digital en docentes y } \\
\text { discentes. } \\
\text { - Afianzan la cultura innovadora en centros, } \\
\text { impulsando proyectos de ciencias con TIC. } \\
\text { - Fomentan las buenas prácticas ligadas al uso de la } \\
\text { RA al servicio de los aprendizajes científicos. } \\
\text { - Activan la creatividad para crear recursos y diseñar } \\
\text { actividades motivadoras. } \\
\text { Para los docentes } \\
\text { - Supone una ocasión idónea para actualizarse y } \\
\text { adquirir nuevos conocimientos acordes con los } \\
\text { avances de la sociedad digital. } \\
\text { - Activa su capacidad organizativa y creativa para } \\
\text { implementar metodologías activas que faciliten el } \\
\text { aprendizaje por proyectos o resolución de } \\
\text { problemas. } \\
\text { - Propicia prácticas motivadoras que incrementan la } \\
\text { comprensión de conceptos abstractos. } \\
\text { - Descubren el potencial de la RA para desarrollar } \\
\text { las competencias científicas en los distintos niveles } \\
\text { educativos. } \\
\text { - Impulsa la creación de recursos didácticos propios } \\
\text { con tecnologías relacionadas con la RA. } \\
\text { - Potencia la explotación de la geolocalización para } \\
\text { abordar contenidos ligados a las ciencias. }\end{array}$ & $\begin{array}{l}\text { Riesgos externos } \\
\text { - Excluyen a quienes no manejan ni poseen tecnologías } \\
\text { (tablets, smartphones, ipad, etc.) } \\
\text { - Hay contextos escolares sin conexiones a Internet de } \\
\text { alto rendimiento. } \\
\text { - Permanentes cambios e introducción de novedosas } \\
\text { tecnologías que la escuela no asimila con agilidad. } \\
\text { - No hay disponibles aplicaciones de RA para abordar } \\
\text { todos los contenidos curriculares de ciencias. } \\
\text { Para los docentes } \\
\text { - Necesitan formación y actualización didáctico- } \\
\text { metodológica para manejar e implementar la RA en el } \\
\text { currículum del área de ciencias. } \\
\text { - Desconocen fórmulas y estrategias para evaluar los } \\
\text { aprendizajes adquiridos por el alumnado con RA. } \\
\text { - Perciben un incremento en su dedicación para } \\
\text { preparar las clases con RA y responder a las } \\
\text { necesidades formativas del alumnado en ciencias. } \\
\text { - Nivel de frustración alto al constatar que la red no } \\
\text { permite siempre activar las aplicaciones RA o no } \\
\text { funcionan los soportes tecnológicos. } \\
\text { - A veces se sienten solos al no contar con grupos de } \\
\text { innovación de referencia que les apoye. } \\
\text { - Algunos lo consideran una pérdida de tiempo al } \\
\text { alejarles del currículum oficial. }\end{array}$ \\
\hline
\end{tabular}


Tabla 9: Continuación

\begin{tabular}{l|l}
\hline Para el alumnado & Para el alumnado \\
- Aumenta su interés por el conocimiento científico. & - Lento proceso de adaptación a las nuevas \\
- Les ayuda a normalizar el uso cotidiano de las & herramientas al no contar con los soportes \\
tecnologías digitales para la búsqueda de & tecnológicos suficientes dentro y fuera del aula. \\
información, resolución de problemas, etc. & - No todos poseen las competencias digitales básicas, \\
- Les facilita la comprensión de hechos y & ralentizando el desarrollo de actividades de carácter \\
fenómenos científicos abstractos que implican & científico apoyadas en RA. \\
dificultad. & - Algunos se distraen jugando con los soportes y \\
- Fomenta en ellos unas actitudes positivas hacia la & recursos tecnológicos, olvidándose de su aplicación \\
ciencia, al acercarlos al medio natural, animales, etc. & para adquirir o afianzar los contenidos educativos. \\
- Activa la indagación sobre los procesos naturales. & - No siempre hay recursos adaptados a las necesidades \\
- Promueve el gusto por la ciencia y las vocaciones & especiales. \\
científicas, al aprender por descubrimiento. & Administración \\
Administración & - Escasa oferta formativa sobre el uso de la RA \\
- Estimula la participación en proyectos y & - Carecen de incentivos y/o apoyos institucionales para \\
comunidades de práctica orientadas a innovar con & impulsar proyectos innovadores de carácter \\
RA en el aula de ciencias. & tecnológico. \\
- Concede acreditaciones a los docentes que & - Insuficiente financiación para dotar de tablets y \\
participan en proyectos de innovación. & programas actuales al centro. \\
& - Encorsetamiento del currículum. \\
\hline
\end{tabular}

\section{Conclusiones}

El desarrollo del proyecto Exp- $\mathrm{R} A$ dio lugar a diferentes experiencias con RA sobre diversos contenidos del currículum de ciencias de Educación Primaria, orientadas a potenciar la competencia científica en el alumnado. Tras su ejecución, los docentes valoraron muy positivamente las prácticas con RA en el aula de ciencias, destacando su contribución al aprendizaje de conocimientos relativos a conceptos y procesos científicos, especialmente aquéllos que pueden presentar más complejidad y abstracción para el alumnado de primaria, como el fenómeno del electromagnetismo o las redes de comunicación, los conceptos relacionados con la geometría, los volúmenes, la tridimensionalidad y el realismo de los órganos del cuerpo humano, etc. Asimismo, consideran que favorecieron su capacidad para describir y explicar fenómenos de la naturaleza y para interpretar los datos recabados, por ejemplo la metamorfosis de la rana y la mariposa, la elaboración de la mantequilla y los helados. En cambio, se ejercitó menos la experimentación científica directa, lo que pudo deberse a las características de las actividades diseñadas por los docentes, dirigidas principalmente hacia otros aspectos de la competencia científica, como la iniciación a la investigación científica básica, al tratarse de alumnado de los distintos niveles de primaria.

En la mayoría de los casos, el nivel de RA incorporado era el más básico, limitado a la creación de códigos QR o coloreado de láminas-marcadores prediseñadas (Quiver y Chromville) en los cursos iniciales de primaria. Sólo se aumentaron elementos con $H p$ Reveal en $6^{\circ}$ con la colaboración de los docentes, dada la complejidad de la creación de auras. A pesar de que el objetivo de esta investigación no era determinar si había un incremento significativo en los logros de aprendizaje del alumnado con la utilización de RA -pues ello hubiera implicado diseñar rúbricas de evaluación ad hoc para cada experiencia- sin embargo sí se ha constatado que su integración ligada a metodologías activas como el Aprendizaje basado en Proyectos ha favorecido la adquisición y/o desarrollo de la competencia científica, a juicio de los docentes implicados en el proyecto, generalmente al rescatar su potencial lúdico y ponerlo al servicio del aprendizaje.

Concretamente, hay unanimidad al destacar el alto grado de motivación y concentración en las tareas a desarrollar, utilizando de forma autónoma los dispositivos móviles para rescatar 
información de la web a partir de códigos QR a modo de gymkhana, logrando implicar a los estudiantes, favorecer el trabajo colaborativo y mejorar del clima de aula. Del mismo modo, el alumnado se implicó en la propuesta de actividades al crear sus propios códigos QR para que los compañeros de otros grupos respondieran a preguntas cuyas respuestas estaban contenidas en los vídeos o web vinculadas a ellos. Los docentes convienen en que las actividades realizadas incrementaron en gran medida aspectos actitudinales, como la conciencia medioambiental y/o respeto a los animales, generando una actitud positiva hacia la ciencia y la experimentación y/o simulaciones a partir de láminas o tarjetas en $3 \mathrm{D}$ de procesos que no se podían observar de forma directa e instantánea (metamorfosis de la rana o mariposa). A ello se agrega la idoneidad de la RA para adoptar metodologías activas basadas en la indagación, capaces de impulsar el trabajo colaborativo a través de estrategias lúdicas o gamificadas que inviten a la superación de niveles, la contestación a baterías de preguntas, la ejecución de tareas o misiones, etc.

Indudablemente, la metodología adoptada en la enseñanza de contenidos científicos, así como las estrategias didácticas empleadas, la concepción sobre la enseñanza que posea el profesorado y los recursos tecnológicos utilizados para acercar la ciencia a los escolares son variables a tener presentes, pues condicionan la eficacia didáctica. A su vez, la percepción de los docentes sobre las aportaciones de la RA a la enseñanza de las ciencias viene condicionada por su formación previa para el manejo de programas y recursos, el diseño de actividades y aplicación de metodologías activas que promuevan la indagación, el aprendizaje por proyectos, la resolución de problemas, etc. Asimismo, el profesorado debe diseñar instrumentos de evaluación de carácter cualitativo -como pueden ser las rúbricas analíticas-, que les permitan constatar los logros de aprendizaje alcanzados del alumnado con la RA.

El proyecto Exp-RA buscó dar respuesta a la necesidad formativa del profesorado, integrándoles en una comunidad de práctica virtual para proporcionarles recursos y ejemplos que les ayudara a iniciarse o a profundizar en los distintos niveles de uso de la RA. Junto a la dimensión formativa del proyecto, era importante contar con los recursos tecnológicos necesarios (conexión a Internet, aplicaciones, dispositivos móviles...) para desarrollar las experiencias, y dispensar apoyo y reconocimiento a los docentes participantes. Sin duda, son elementos que inciden en la implicación del profesorado, así como en su percepción sobre la eficacia de las actividades diseñadas, pues sucede que este tipo de innovaciones no terminan de consolidarse debido a la inseguridad que genera la precariedad tecnológica de muchas escuelas.

Así, conscientes de que la implementación de la RA supone un desafío para la enseñanza de ciencias, se hace patente la necesidad de proporcionar instrumentos y apoyos necesarios para favorecer este tipo de actividades innovadoras, que en ningún caso pretenden sustituir a las experiencias de observación directa de los fenómenos naturales. Es ineludible formar al profesorado para que adopte metodologías adecuadas que permitan integrarla, aprovechando las oportunidades que brinda para activar la competencia científica en primaria.

\section{Referencias}

Cañal, P. (2012a) La evaluación de la competencia científica requiere nuevas formas de evaluar los aprendizajes. En E. Pedrinaci (Coord.) 11 ideas clave: El desarrollo de la competencia cientifica (pp. 241-267). Barcelona: Graó.

Cañal, P. (2012b) ¿Cómo evaluar la competencia científica?. Investigación en la Escuela 78, 5-15.

Cañal, P., García-Carmona, A. y Cruz-Guzmán, M. (2016) Didáctica de las Ciencias Experimentales en Educación Primaria. Madrid: Paraninfo. 
Chen, K.H. y Tsai, C-C. (2013) Affordances of Augmented Reality in Science Learning: Suggestions for Future Research. Journal of Science Education and Technology 22(4), 449462. Doi:10.1007/s10956-012-9405-9

Cornejo, R. y Redondo, J. (2001) El clima escolar percibido por los alumnos de enseñanza media. Una investigación en algunos liceos de la Región Metropolitana. Recuperado de https://bit.ly/2INcV7c

Cawood, S. y Fiala, M. (2008) Augmented Reality: A Practical Guide. Denver: Pragmatic Bookshelf.

Chacón, C. (2006) Formación inicial y competencia comunicativa: percepciones de un grupo de docentes de inglés. Educere 10(32), 121-130.

De Miguel, M. (2006) Metodologías para optimizar el aprendizaje. Segundo objetivo del Espacio Europeo de Educación Superior. Revista Interuniversitaria de Formación del Profesorado 20(3), 71-91.

Del Moral, M.E., Villalustre, L. y Neira-Piñeiro, M.R. (2014) Variables asociadas a la cultura innovadora con TIC en escuelas rurales. Profesorado. Revista de Currículo y Formación del Profesorado 18(3), 9-25.

Franco-Mariscal, A.J. (2015) Competencias científicas en la enseñanza y el aprendizaje por investigación. Un estudio de caso sobre corrosión de metales en secundaria. Enseñanza de las Ciencias 32(2), 693-695. DOI: 10.5565/rev/ensciencias.1410

Fracchia, C.C., Alonso de Armiño, A.C., y Martíns, A. (2015) Realidad Aumentada aplicada a la enseñanza de Ciencias Naturales. Revista Iberoamericana de Educación en Tecnología y Tecnología en Educación (TE \& ET) 16, 7-15.

García-Ruiz, R., y Zubizarreta, A.C. (2012) La formación permanente del profesorado basada en competencias. Estudio exploratorio de la percepción del profesorado de Educación Infantil y Primaria. Educatio Siglo XXI: Revista de la Facultad de Educación 30, 297-322.

Gil, J. (2014) Metodologías didácticas empleadas en las clases de ciencias y su contribución a la explicación del rendimiento. Revista de Educación 366, 190-214. DOI: 10.4438/1988592X-RE-2014-366-271

Gobierno Vasco (2009) Competencias Básicas. Educación Primaria. Recuperado de https://bit.ly/2J0oTK7

González-Rogado, A.B., Vivar-Quintana, A.M., y Elorza, I. (2013, November) Augmented safety in the laboratory with mobile technology. In Proceedings of the First International Conference on Technological Ecosystem for Enhancing Multiculturality. New York: ACM. DOI: $10.1145 / 2536536.2536601$

Guisasola, J., y Morentin, M. (2007) ¿Qué papel tienen las visitas escolares a los museos de Ciencias en el aprendizaje de las Ciencias? Una revisión de las investigaciones. Enseñanza de las Ciencias 25(3), 401-414.

Gutiérrez-García, C., Pérez-Pueyo, Á., Pérez-Gutiérrez, M., y Palacios-Picos, A. (2011) Percepciones de profesores y alumnos sobre la enseñanza, evaluación y desarrollo de competencias en estudios universitarios de formación de profesorado. Cultura y Educación 23(4), 499-514. DOI: https://doi.org/10.1174/113564011798392451

Junta de Andalucía (2007a) Decreto 230/2007, de 31 de julio, por el que se establecen la ordenación y las enseñanzas correspondientes a la Educación Primaria obligatoria en Andalucía. BOJA de 8 de agosto de 2007. 
Junta de Andalucía (2007b) Decreto 231/2007, de 31 de julio, por el que se establecen la ordenación y las enseñanzas correspondientes a la Educación Secundaria Obligatoria en Andalucía. BOJA de 8 de agosto de 2007.

Linn, M.C., Davis, E.A. y Bell, P. (2004) Internet Environments for Science Education. Mahwah, Nueva Jersey: Erlbaum.

McNamara, C. (1999) Strengths, Weaknesses, Opportunities and Threats (SWOT Analysis). Strategic Planning (in nomprofit or for-profit organizations). Recuperado de https://bit.ly/2PxvMUo

Ministerio de Educación y Ciencia (2006) Real Decreto 1513/2006, de 7 de diciembre, por el que se establecen las enseñanzas mínimas correspondientes a la Educación Primaria. BOE de 8 de diciembre de 2006.

Ministerio de Educación y Ciencia (2007) Real Decreto 1631/2006, de 26 de diciembre, por el que se establecen las enseñanzas mínimas correspondientes a la Educación Secundaria Obligatoria. BOE de 5 de enero de 2007.

Minner, D.D., Levy, A.J. y Century, J. (2010) Inquiry-Based Science. Instruction. What Is it and Does it Matter? Results from a Research Synthesis Years 1984 to 2002. Journal of Research in Science Teaching 47(4), 474- 496. DOI: https://doi.org/10.1002/tea.20347

OCDE (2006) PISA 2006. Marco de la evaluación. Conocimientos y babilidades en Ciencias, Matemáticas y Lectura. Madrid: Santillana.

OCDE (2017) PISA. Marco de Evaluación y de Análisis de PISA para el Desarrollo: lectura, matemáticas y ciencias. Versión preliminar. París: OCDE.

Pedrinaci, E. (2012) El ejercicio de una ciudadanía responsable exige disponer de cierta competencia científica. En E. Pedrinaci (Coord.). 11 ideas clave. El desarrollo de la competencia cientifica (pp. 15-37). Barcelona: Graó.

Pérez Buendía, C. (2014) Los cinco reinos. Diseño de materiales usando las nuevas tecnologías y evaluación de aprendizajes. Enseñanza de las Ciencias 32(3), 693-695. Doi: $10.5565 / \mathrm{rev} /$ ensciencias. 1410

Rebollo, M. (2010) Análisis del concepto de competencia científica: definición y sus dimensiones. En I Congreso de inspección de Andalucia: Competencias básicas y modelos de intervención en el aula. Mijas, Costa: Junta de Andalucía. Consejería de Educación.

Rojas Salgado, M.E. (2017) Los recursos tecnológicos como soporte para la enseñanza de las ciencias naturales. Hamut'ay. Revista semestral de Divulgación Científica 4(1), 85-95. Doi: 10.21503/hamu.v4i1.1403

Romero, M., y Quesada, A. (2014) Nuevas tecnologías y aprendizaje significativo de las ciencias. Enseñanza de las Ciencias 32(1), 101-115. DOI: 10.5565/rev/ensciencias.433 ISS

Savitz-Romer, M., Rowan-Kenyon, H.T., y Fancsali, C. (2015) Social, Emotional, and Affective Skills for College and Career Success. Change: The Magazine of Higher Learning, 47(5), 18 27. DOI: https://doi.org/10.1080/00091383.2015.1077667

Schroeder, C., Scott, T., Tolson, H., Huang, T. y Lee, Y. (2007) A Meta- Analysis of National Research: Effects of Teaching Strategies on Student Achievement in Science in the United States. Journal of Research in Science Teaching 44(10), 1436-1460. Doi: 10.1002/tea.20212 
Solano, C.A., Casas J.F. y Guevara, J.C. (2015) Aplicación móvil de realidad aumentada para la enseñanza de la clasificación de los seres vivos a niños de tercer grado. Ingeniería 20(1), 101-115.

Stojanova, A., Kocaleva, M., Manevski, V., Kocev, I., y Delipetrev, B. (2015, June) Model of crowdsource environmental application based on mobile photos. VI International Conference of Information Technology and Development of Education (ITRO 2015). Zrenjanin, Serbia: University of Novi Sad.

Valverde-Crespo D., Pro-Bueno A., González-Sánchez, J. (2018) La competencia informacional-digital en la enseñanza y aprendizaje de las ciencias en la educación secundaria obligatoria actual: una revisión teórica. Revista Eureka sobre Enseñanza y Divulgación de las Ciencias 15(2), 2105-2115. DOI: https://doi.org/10.25267/Rev_Eureka_ensen_divulg_cienc.2018.v15.i2.2105

Villalustre, L. y Del Moral, M.E. (2016a) Itinerarios interactivos con geolocalización y realidad aumentada para un aprendizaje ubicuo en la formación inicial de docentes de educación infantil. En L. Villalustre y M.E. Del Moral (coords.) (2016) Experiencias interactivas con realidad aumentada en las aulas (pp. 31-53). Barcelona: Octaedro.

Villalustre, L. y Del Moral, M.E. (Coords.) (2016b) Experiencias interactivas con realidad aumentada en las aulas. Barcelona: Octaedro.

Villalustre, L. y Del Moral, M.E. (2017) Juegos perceptivos con realidad aumentada para trabajar contenido científico. Educaşão, Formação \& Tecnologias 10(1), 36-46. 